\title{
Effectiveness of a chronic disease self-management program in Mexico: A randomized controlled study
}

\author{
Maria Isabel Peñarrieta de Córdova ${ }^{* 1}$, Rodrigo Leon ${ }^{1}$, Tranquilina Gutierrez ${ }^{1}$, Nelda Mier ${ }^{2}$, Olga Banda ${ }^{1}$, Magdalena \\ Delabra $^{3}$ \\ ${ }^{1}$ Facultad de Enfermería, Universidad Autónoma de Tamaulipas, Tampico, Tamaulipas, México \\ ${ }^{2}$ Texas A\& M School of Public Health, McAllen, TX, United States \\ ${ }^{3}$ Facultad de Enfermería, Universidad Autónoma de Coahuila, Saltillo, Coahuila, México
}

Received: December 27, 2016

Accepted: February 7, 2017

Online Published: February 21, 2017

DOI: $10.5430 /$ jnep.v7n $7 \mathrm{p} 87$

URL: https://doi.org/10.5430/jnep.v7n7p87

\begin{abstract}
Objective: To assess the effectiveness of a Spanish-language version of the Stanford Chronic Disease Self-management Program among adults who received medical care in community health centers in Mexico.

Methods: This was a prospective, randomized study with Mexican users of community health centers in Tampico, Mexico, conducted between September 2015 and July 2016. A total of 120 adults aged 18 years or older were randomly assigned to intervention $(n=62)$ and control $(n=58)$ groups. Data were collected at baseline and at 3 and 6 months post intervention using a structured questionnaire. A repeated measures ANOVA was used for data analysis.

Results: Statistically significant differences were found in intervention participants at 3 and 6 months post intervention compared to baseline and the control group for self-management behaviors, including: social activity limitation, quality of life perception, depression, stress, physical activity, communication with physicians, adherence to physician visits, and self-management behaviors.

Conclusions: Chronic disease self-management programs (CDSMP) with Mexican adults in community settings are effective in improving their health and self-management behaviors. Further research is needed to assess CDSMP in Mexico and Latin America using objective measurements and examining health outcomes and self-management maintenance over longer periods of time.
\end{abstract}

Key Words: Chronic disease, Self-management, Randomized controlled study, Community health services, Chronic disease, Mexico, Latin America

\section{INTRODUCTION}

Chronic illnesses, including heart disease, diabetes, stroke, cancer and chronic respiratory disease, are the leading cause of mortality worldwide. ${ }^{[1]}$ This increasing chronic disease epidemic together with low levels of treatment adherence pose high social and economic costs to individuals, families, and government sectors. Research shows that one-fourth of individuals suffering from chronic diseases receive adequate care, but only half of them adhere to clinical treatment. ${ }^{[2]}$ Chronic diseases are by far the most significant challenge faced by many countries in the world, including Mexico, due to the large numbers of individuals affected, the increasing contribution of these diseases to both overall mortality rates and premature disability, and high costs of treatments. ${ }^{[3]}$

\footnotetext{
* Correspondence: Maria Isabel Peñarrieta de Córdova; Email: pcordoba@uat.edu.mx; Address: Facultad de Enfermería, Universidad Autónoma de Tamaulipas, Tampico, Tamaulipas, México.
} 
Chronic diseases are also the leading cause of mortality and morbidity in Mexico at the national level. Between 2000 and 2010 Mexico experienced an increase in mortality rates related to chronic disease as follows: diabetes, $61 \%$; ischemic heart, 50\%; neoplasia, 20\%; circulatory disorders, $35 \%$; and cerebrovascular disease, $18 \%$. Prevalence rates of chronic diseases are even higher in Northern border Mexican states compared to national rates (9.2\% versus $10.3 \%$, respectively). Data from four national Mexican surveys 1999, 2000, 2006, 2012 , indicate there are a number of critical issues that must be addressed before chronic illnesses are reduced in Mexico including: the increasing number of at-high risk individuals; the high percentage of undiagnosed patients with one or more chronic diseases; and the ineffectiveness of clinical treatments which tend to be complex and lengthy. ${ }^{[4]}$

Due the high social and economic costs of chronic disease in many countries there is now an increased interest in chronic disease self-management programs (CDSMP). ${ }^{[5,6]}$ CDSMP programs are based on self-efficacy theory and are designed to improve an individual's self-confidence in managing their health, through skill development, symptom control, social persuasion, and strategies to deal with negative emotions, such as fear and depression. ${ }^{[7]}$

Research shows that self-efficacy is one means in psychosocial interventions to improve health outcomes. ${ }^{[8]}$ Selfmanagement programs aim to increase patients' knowledge, skills, and self-efficacy not only to educate them on how to manage their disease, but also to collaborate effectively with their health providers. Research found that poor communication between chronic disease patients and their providers and the lack of integrated health plans has a negative impact in care provision. Conversely, studies show that chronic disease prevention and treatments are more effective in integrated care models, which emphasize an active collaboration between patients and health professionals. ${ }^{[9-11]}$ In addition, extensive research in the past 20 years indicate CDSMP programs are effective in improving health and reducing hospitalizations and emergency room use. ${ }^{[12]}$ A meta-analysis and systematic literature review indicate that CDSMP programs are effective in reducing risk factors among patients with cerebrovascular disease. ${ }^{[13]}$ Another study with patients with diabetes found that their $\mathrm{HbA} 1 \mathrm{c}$ levels decreased significantly after being exposed to self-management programs. ${ }^{[14]}$ Although there is considerable research examining the effectiveness of CDSMP programs in English and Spanish speaking populations in the United States and Europe, there is scarce literature investigating the application of these programs in Mexico and other Latin American countries. Therefore, the purpose of this study was to assess the effectiveness of the Stanford Chronic Disease Self-Management Pro- gram Spanish-language version Tomando Control de suSalud among Mexican adults who received healthcare in community health centers in Mexico.

\section{MethodS}

\subsection{Study design}

A randomized, prospective, controlled design was used to investigate the effectiveness of the Stanford Chronic Disease Self-Management Program Spanish-language version Tomando Control de su Salud. The study was implemented during the period between September 2015 and July 2016. This was a six-week intervention and assessment data were collected at baseline and at 3 and 6 months post intervention. This study was part of the exploratory phase of the Binational Peru-Mexico Project. Participants were individuals receiving healthcare through chronic disease programs at seven community health centers in Tampico, Tamaulipas, Mexico. A working team comprised of two nurses was established at each community health center and was responsible of delivering the program and collecting assessment data. Working teams invited patients at each community health center to participate in the study. Inclusion criteria were: individuals 18 years of age or older; male or female; having being diagnosed with one chronic disease or more for more than three months; being able to respond to a questionnaire without assistance. Exclusion criteria were: individuals with visual and/or hearing problems; being pregnant. Participants who agreed to be part of the study signed a consent form. A total of 205 participants recruited into the study were randomly assigned to an intervention group $(\mathrm{n}=108)$ or a control group $(n=97)$. However, only participants who attended four or more intervention sessions and completed all the assessments were included in data analyses. The final sample contained 120 participants (see Figure 1).

This study was approved by the Institutional Review Board from Facultad de Enfermería Universidad Autónoma de Tamaulipas.

\subsection{The intervention}

The Stanford CDSMP Spanish language version Tomando Control de su Salud was 18 hours given in six weeks. Each session had a maximum of 15 participants 18 years of age or older and with one or more disease. Each session was led by two nurses known as Program Leaders. They received 20 hours of training and were instructed to deliver the program according to the Stanford Self-Management Program Manual (see Table 1). Each participant received a copy of a book titled Tomando Control de suSalud to use as a reference. ${ }^{[15]}$ 


\begin{tabular}{c|c}
\hline \multicolumn{2}{c}{ Total 205 (100\%) } \\
\hline Intervention & Control \\
\hline $108(53 \%)$ & $9747 \%)$ \\
\hline
\end{tabular}

3 months post intervention

\begin{tabular}{c|c}
\hline \multicolumn{2}{c}{ Total 150 (73\%) } \\
\hline Intervention & Control \\
\hline $77(38 \%)$ & $73(36 \%)$ \\
& \\
\hline
\end{tabular}

Figure 1. Study population baseline

Table 1. "Tomando control de susalud" sessions and topics

\begin{tabular}{ll}
\hline Session & Topics \\
\hline 1 & Symptoms management \\
& Eating better and being active \\
& Sleeping well all night \\
& Making and action plan \\
& Feedback/problem solving \\
& Nutrition \\
& Fitness/exercise \\
& Practicing exercises \\
& Falls prevention and improving balance \\
& Making an action plan \\
& Feedback/Making an action plan \\
& Choosing healthy foods \\
& Making decisions \\
& Better breathing \\
& Relaxation \\
& Feedback/Making an action plan \\
& Food label reading \\
& Fitness/exercise \\
& Depression \\
& Positive thinking \\
& Feedback/Making an action plan \\
& Healthy weight \\
& Communication \\
& Medications \\
& Assessing home remedies and alternative treatments \\
& Feedback \\
& Working with your health care professional \\
& Practicing exercises \\
& Sharing successes \\
& Future plans \\
\hline & \\
& \\
& \\
&
\end{tabular}

Published by Sciedu Press

\subsection{Measures}

Baseline and post intervention data were collected by nursing senior students, who were supervised by a Nursing Professor. Data collectors administered a structured questionnaire to each participant to assess sociodemographics, self-report health status, program attendance, and outcomes measures.

Participants' sociodemographics and health status measures included, sex, age, education level, type of health insurance, number of chronic diseases, number of family members, and self-report medical diagnosis related to diabetes and hypertension.

This study also included the following outcome measures: social activity limitation, depression, stress, quality of life perception, physical activity, communication with physician, self-management behaviors, and utilization of healthcare services. ${ }^{[16-18]}$ Visual analog scales developed by Stanford University were used for measuring depression and stress. ${ }^{[16]}$ Visual analog scales are widely used in research. ${ }^{[19,20]}$ The scales used in this study differed from other scales in the number and heights of bars (10) and shade intensities. The study scales had a correlation of $r=0.72$ and the 2-weeks test-retest reliability of the visual numeric scale was $0.64{ }^{[20]}$ Health-related behaviors measures included frequency of physical activity and communication with physician; both measures have been tested for validity and reliability. ${ }^{[21]}$ Self-management behaviors were assessed using the Partners in Health scale (PHS), which was previously validated in Mexican and Peruvian populations by the authors of this study. ${ }^{[22,23]}$ PHS measures self-management behaviors by one global domain and 3 specific domains: disease knowledge, treatment adherence, and management of physical, emotional, and social impact. Four types of healthcare utilization were also measured: adherence to regular physician visits, emergency room visits, hospitalizations, and hospital stays. Participants were asked about how many times in the past six months they used this type of healthcare services. Previous research shows a high correlation between patients' self-report of healthcare utilization and medical records. ${ }^{[24]}$

\subsection{Statistical analysis}

Statistical analyses were performed with SPSS version 21. Descriptive, mean differences, and repeated measures ANOVA analyses were used to compare outcomes between groups and within-subjects at baseline and 3 and 6 months intervention. The significant level was set at $\alpha=0.05$.

\section{RESULTS}

\subsection{Demographic characteristics}

Both intervention and control group participants had similar socio-demographic and clinical characteristics, as shown 
in Table 2. There were no significant differences between groups, except for type of health insurance $(p<.009)$. The majority of participants were female with an age range of 27-82 years and their mean ages were 59.6 and 57.0 in the intervention and control group, respectively. Participants had a mean education level of 7.4 and 7.0 years in the intervention and control group, respectively. About half of participants in both groups reported having more than one chronic disease, and also have been diagnosed with diabetes and hypertension.

Table 2. Demographic characteristics of the study sample $(n=120)$ by intervention and control group

\begin{tabular}{|c|c|c|c|c|c|}
\hline & \multicolumn{2}{|c|}{ Intervention 62 (100\%) } & \multicolumn{2}{|c|}{ Control 58 (100\%) } & \multirow{2}{*}{ Sig. } \\
\hline & $\#$ & $\%$ & $\#$ & $\%$ & \\
\hline \multicolumn{6}{|l|}{ Sex } \\
\hline Female & 49 & 79 & 42 & 72.4 & \\
\hline Male & 13 & 21 & 16 & 27.6 & \\
\hline Age & $\mu: 59.6$ & Rank: 27-82 & $\mu: 57$ & Rank: 37-79 & \\
\hline Education (years) & $\mu: 7.4$ & Rank: 0-16 & $\mu: 7$ & Rank: 0-17 & \\
\hline \multicolumn{6}{|l|}{ Number of chronic diseases } \\
\hline One & 28 & 45.2 & 29 & 50 & \\
\hline More than one & 34 & 54.8 & 29 & 50 & \\
\hline \multicolumn{6}{|l|}{ Type of health insurance } \\
\hline Popular insurance & 50 & 80.6 & 56 & 96.6 & \multirow{4}{*}{.009} \\
\hline Social insurance & 10 & 16.1 & 0 & 0 & \\
\hline Private insurance & 0 & .0 & 1 & 1.7 & \\
\hline Other & 2 & 3.2 & 1 & 1.7 & \\
\hline Number of family members & $\mu: 4$ & Rank: $1-10$ & $\mu: 3$ & Rank: 1-6 & \\
\hline \multicolumn{6}{|l|}{ Medical diagnoses } \\
\hline Diabetes & 32 & 51.6 & 28 & 48.3 & \\
\hline Hypertension & 30 & 48.4 & 30 & 51.7 & \\
\hline
\end{tabular}

\subsection{Attrition}

Participants included in this study attended four or more program sessions. As shown in Table 3, the majority of participants $(62 \%)$ attended all of six program sessions. Only one person dropped out from the intervention after attending two sessions, and another one dropped out after the third session.

\subsection{Outcome analyses}

The effectiveness of the intervention was assessed in relation to the following outcomes: 1) health status, 2) health-related behaviors, 3) healthcare utilization, and 4) self-management behaviors at baseline and at 3 and 6 months post intervention (see Table 4).

Table 3. Number of program attendees by health center and session

\begin{tabular}{lllllll}
\hline \multirow{2}{*}{ Health center } & \multicolumn{2}{c}{ Intervention session } & & \multicolumn{2}{c}{ Total } \\
\cline { 2 - 6 } & $\mathbf{2}$ & $\mathbf{3}$ & $\mathbf{4}$ & $\mathbf{5}$ & $\mathbf{6}$ & 12 \\
\hline Tampico I & & 1 & 5 & 6 & 12 \\
Tampico II & 1 & 3 & 2 & 8 & 12 \\
Borreguera & & & & 12 & 12 \\
Tolteca & & & 9 & 1 & 10 \\
Esfuerzo obrero & & & 3 & 7 & 10 \\
Madero & & & 4 & 6 & 13 \\
Francisco villa & 1 & 1 & 23 & 50 & 81 \\
Total & & & & & \\
\hline
\end{tabular}


Table 4. Comparison of the mean change scores of program measures at baseline and 3 and 6 months post intervention

\begin{tabular}{|c|c|c|c|c|c|c|c|c|}
\hline \multirow[t]{2}{*}{ Variables } & $\begin{array}{l}\text { Baseline } \\
(n=62)\end{array}$ & $\begin{array}{l}\text { Baseline } \\
(n=58)\end{array}$ & $\begin{array}{l}\text { Changes at } 3 \\
\text { months post } \\
\text { intervention } \\
(n=62)\end{array}$ & $\begin{array}{l}\text { Changes at } 3 \\
\text { months post } \\
\text { intervention } \\
(n=58)\end{array}$ & $\begin{array}{l}\text { Changes at } 6 \\
\text { months post } \\
\text { intervention } \\
(n=62)\end{array}$ & $\begin{array}{l}\text { Changes at } 6 \\
\text { months post } \\
\text { intervention } \\
(n=58)\end{array}$ & $\begin{array}{l}\text { Within } \\
\text { groups }\end{array}$ & $\begin{array}{l}\text { Groupx- } \\
\text { time } \\
\text { intera- } \\
\text { ction }\end{array}$ \\
\hline & $\begin{array}{l}\text { Interven- } \\
\text { tion }\end{array}$ & Control & Intervention & Control & Intervention & Control & $\begin{array}{l}\text { MR } \\
\text { ANOVA }\end{array}$ & $p$ \\
\hline \multicolumn{9}{|l|}{ Health status* } \\
\hline Social activity limitation*(0-16) & 297 & 2.14 & 2.31 & 3.64 & 1.85 & 1.69 & .008 & .028 \\
\hline Depression*(0-24) & 5.48 & 4.29 & 3.37 & 4.00 & 3.85 & 3.34 & .012 & .154 \\
\hline Stress* $(1-10)$ & 4.63 & 3.74 & 4.00 & 3.74 & 3.61 & 3.05 & .020 & .591 \\
\hline Quality of life perception $†(1-10)$ & 6.74 & 6.69 & 8.14 & 6.88 & 7.32 & 6.71 & .002 & .027 \\
\hline \multicolumn{9}{|l|}{ Health behaviors } \\
\hline Participant did exercise last week & $58 \%$ & $43 \%$ & $74 \%$ & $40 \%$ & $76 \%$ & $59 \%$ & $P<.05$ & \\
\hline Communication with physician†(0-15) & 3.58 & 3.56 & 4.67 & 3.56 & 4.69 & 3.56 & .023 & .001 \\
\hline Understand medical instructions $†(0-4)$ & 3.23 & 3.43 & 3.56 & 3.21 & 3.31 & 3.40 & .841 & .011 \\
\hline \multicolumn{9}{|l|}{ Healthcare utilization } \\
\hline $\begin{array}{l}\text { Regular physician visits in the past } 6 \\
\text { months }\end{array}$ & 5.26 & 4.31 & 5.53 & 5.34 & 6.27 & 5.15 & .002 & .177 \\
\hline $\begin{array}{l}\text { Emergency room visits in the past } 6 \\
\text { months }\end{array}$ & 0.29 & 0.15 & 0.40 & 0.05 & 0.19 & 0.034 & .309 & .367 \\
\hline Hospitalizations in the past 6 months & 0.24 & 0.22 & 0.11 & 0.10 & 0.09 & 0.07 & .197 & .995 \\
\hline Hospital stays in the past 6 months & 0.16 & 0.26 & 0.31 & 0.19 & 0.09 & 0.31 & .881 & .303 \\
\hline \multicolumn{9}{|l|}{ Self-management behaviors } \\
\hline Global domain $\dagger(0-100)$ & 82.90 & 79.72 & 90.27 & 71.17 & 84.21 & 74.22 & .348 & .000 \\
\hline Disease knowledge $+(0-100)$ & 74.76 & 61.40 & 84.89 & 62.95 & 77.85 & 61.34 & .046 & .200 \\
\hline Treatment adherence $+(0-100)$ & 86.10 & 84.10 & 90.35 & 71.88 & 85.40 & 76.64 & .026 & .000 \\
\hline $\begin{array}{l}\text { Management of physical, emotional, } \\
\text { and social impact } †(0-100)\end{array}$ & 82.55 & 82.50 & 92.27 & 74.07 & 85.66 & 77.29 & .665 & .000 \\
\hline
\end{tabular}

Results showed that there were significant differences in main time effect and groupxtime interaction effect with the intervention group showing a significant improvement in Social Activity Limitation at six months post intervention ( $p$ $<$.028). A significant main time effect was also observed in depression and stress variables in the intervention group. Mean scores in depression and stress decreased significantly in the intervention group at each point in time $(p<.012$ and $p<.020$, respectively). Within groups, between groups, and group $\times$ time interaction analyses showed positive significant differences in Quality of Life Perception in the intervention group.

There were significant changes in physical activity and communication with physicians. A significant increase in both variables were observed in the intervention group compared to the control group. The percentage of participants in the intervention group reporting physical activity increased from $58 \%$ at baseline to $76 \%$ at 6 months post intervention ( $p$ $<.05)$. The mean score in communication with physicians increased from 3.8 at baseline to 4.69 at 6 months post intervention.

Within-group and between-group analyses indicated a significant increase among intervention participants in the ad- herence to regular physician visits at 2 points in time postintervention.

Within-group, between-group, and group $\times$ time interaction analyses showed positive significant differences in the mean scores of the intervention group for global domain, disease knowledge, treatment adherence, and management of physical, emotional, and social impact at 3 and 6 months post intervention. Compared to baseline, the highest mean score increases in all four measures in the intervention group were observed at 3 months post-intervention.

In the control group, negative significant differences at postintervention were observed in mean global domain, treatment adherence, and management of physical, emotional, and social impact scores. No significant differences were found over time in the mean knowledge score in the control group.

\section{Discussion}

The purpose of this study was to assess the effectiveness of the Stanford CDSMP Spanish-language version Tomando Control de su Salud (Tomando) among users who had one or more chronic disease and received healthcare at community health centers in Mexico. Findings showed that the intervention was effective in improving social activity limita- 
tion, depression, stress, and quality of life perception among participants exposed to the program. Previous studies examining the effectiveness of the CDSPM English-version and Tomando Control de su Salud targeting Spanish-speaking Hispanics in the United States found similar results. ${ }^{[5,25-30]}$

The ability to communicate with physicians is a significant self-management behavior for persons with chronic illnesses. Chronic disease self-management programs educate patients play a central role in making decisions and being responsible for managing their disease. Good communication skills help patients not only explain their health issues, but also build a doctor-patient relationship based on shared perceptions, goals, and treatments. This type of communication is not always easy to achieve because it requires that both doctor and patient accept and understand the active role patients have in negotiating healthcare services and treatments for themselves. ${ }^{[31,32]}$ However, this study showed that Tomando was effective in improving communication between intervention participants and their doctors.

It is well documented that being active prevents or delays the onset of complications in persons with chronic disease. This study found that the level of physical activity among participants attending Tomando increased significantly. This resonates with previous research investigating the effects of the Stanford CSMP. ${ }^{[33,34]}$

Twenty percent of users at the community health centers in this study did not adhere to regular physician visits, increasing their risk of developing complications. Our findings showed a statistically significant increase in the adherence to regular physician visits among participants exposed to Tomando. However, no significant changes were found among intervention participants in room emergency visits or hospitalizations. This is in contrast to previous research showing that the Stanford CDSMP reduced emergency healthcare utilization. Inconsistent results with previous studies may be explained by the short-term exposure of intervention participants to Tomando. ${ }^{[35]}$

Tomando also produced significant positive differences in self-management behaviors among intervention participants related to global domain, disease knowledge, treatment adherence, and management of physical, emotional, and social impact. It is worth noting that these variables are considered the basic principles of chronic-disease management. ${ }^{[36]}$ This study results resonated with previous research. ${ }^{[37,38]}$ It was intriguing to find that compared to baseline data the mean scores in these variables were higher at 3 months postintervention. These findings and previous research suggest the need to develop and test additional strategies that can maintain self-management behaviors over time.

\section{Limitations}

The short-term follow-up of the study and the small sample size limits generalizations. Furthermore, dependent and independent constructs were measured using self-reporting questionnaires potentially carrying respondent biases.

\section{Conclusions}

Study results suggest that evidence-based chronic disease self-management programs with Mexican adults receiving healthcare at community health centers are effective in improving their health status and self-management behaviors. Despite its limitations, to the best of our knowledge this may be the first study in Mexico and the Latin America documenting the effectiveness of a chronic disease self-management program in community settings. Further research is needed to assess the effectiveness of CDSMP programs in Latin American populations using clinical, objective measurements and investigating the feasibility of health maintenance over longer periods of time.

\section{ACKNOWLEDGEMENTS}

This study was funded by the Mexican Federal Government through Proyecto de REDES and Proyecto Catedra. The funding source did not have any involvement in study design, data collection, analysis and interpretation of data, manuscript writing, and either was involved in the decision to submit the study for publication.

\section{CONFLiCTS OF INTEREST DisClOSURE}

The authors declare that there is no conflict of interest.

\section{REFERENCES}

[1] World Health Organization (WHO). A Global Brief on Hypertension: Silent Killer, Global Public Health Crisis [Online]. 2013. Available from: http://www. thehealthwell.info/node/466541 [Accessed: 27th December 2016].

[2] Hart JT. Rule of halves: implications of increasing diagnosis and reducing dropout for future workload and prescribing costs in pri- mary care. The British Journal of General Practice. 1992; 42(356): 116-119. PMid: 1493028

[3] Organización Panamericana de la salud Cuidados innovadores para las condiciones crónicas: Organizacion y prestación de atención de alta calidad a las enfermedades crónicas no transmisibles en las Américas. 2013, Washington, DC: OPS.

[4] Aguilar-Salinas CA Las enfermedades crónicas no transmisibles, el 
principal problema de salud en México. Salud Publica de México, 2013,55(Sumplemento 2), s437-s350.

[5] Coleman K, Austin BT, Brach C, et al. Evidence on the chronic care model in the new millennium. Health Affairs (Project Hope). 2009; 28(1): 75-85. PMid:19124857 https://doi.org/10.1377/hlth aff. 28.1 .75

[6] Hoffman C, Rice D, Sung HY. Persons, with chronic conditions. Their prevalence and costs. JAMA. 1996; 276(18): 14731479. PMid:8903258 https://doi.org/10.1001/jama. 1996. 03540180029029

[7] Kulinski KP, Boutaugh M, Smith ML, et al. Settingthestage: measureselection, coordination, and data collectionfor a nationalselfmanagementinitiative. Front Public Health. 2015.

[8] Crosby LE, Joffe NE, Peugh J, et al. Pilot of the Chronic Disease Self-Management Program for Adolescents and Young Adults With Sickle Cell Disease. Journal of Adolescent Health. 2017; 60(1): 120123. PMid:27793727 https://doi.org/10.1016/j.jadoheal th. 2016.08.022

[9] Bandura A. Self-Efficacy: The Exercise of Control. New York: W. H. Freeman. 1997.

[10] Heisler M, Bouknight RR, Hayward RA, et al. The Relative Importance of Physician Communication, Participatory Decision Making, and Patient Understanding in Diabetes Self-management. Journal od General Internal Medicine. 2002; 17(4): 243-252.

[11] Fortin M, Chouinard MC, Dubois MF, et al. Integration of chronic disease prevention and management services into primary care: a pragmatic randomized controlled trial (PR1MaC). CMAJ Open. 2016; 4(4): E588-E598. PMid:28018871 https://doi.org/10.9778/ cmajo. 20160031

[12] Youngwerth J, Twaddle M. Cultures of Interdisciplinary Teams: How to Foster Good Dynamics. Journal of Palliative Medicine. 2011; 14(5): 650-4. PMid:21476853 https://doi .org/10.1089/jpm . 2010.0395

[13] Lorig KR, Sobel DS, Stewart AL, et al. Evidence suggesting that a chronic disease self-management program can improve health status while reducing hospitalization: A randomized trial. Medical Care. 1999; 37(1): 5-14. https://doi.org/10.1097/00005650-199 901000-00003

[14] Sakakibara BM, Kim AJ, Eng JJ. A Systematic Review and MetaAnalysis on Self-Management for Improving Risk Factor Control in Stroke Patients. International Journal Behavioral Medicine. 2016. 1-12 p.

[15] Lorig K, González V, Laurent D. Tomando control de su salud: Una guía para el manejo de las enfermedades del corazón, diabetes, asma, bronquitis, enfisema y otros problemas crónicos (2da ed.). Bull Publishing Company. 2007.

[16] Adams P, Marano M. Current estimates from the National Health Interview. National Center for Health Statistics. Vital Health Stat. $1995 ; 10(193)$

[17] Fries JF, Spitz P, Kraines RG, et al. Measurement of patient outcome in arthritis. Arthritis Rheum. 1980; 23(2): 137-45. https: //doi.org/10.1002/art.1780230202

[18] Ramey D, Raynauld J, Fries J. The health assessment questionnaire 1992: status and review. Arthritis Care and Research.1992; 5(3): 11929. PMid:1457486 https://doi.org/10.1002/art.17900503 03

[19] Downie W, Leatham P, Rhind V, et al. Studies with pain rating scales. Annals of the Rheumatic Diseases. 1978; 37(4): 378-81. https://doi.org/10.1136/ard.37.4.378

[20] González V, Stewart A, Ritter P, et al. Translation and validation of arthritis outcome measures into Spanish. Arthritis and Rheumatism.
1995; 38(10): 1429-46. PMid:7575693 https://doi.org/10.1 002/art. 1780381010

[21] Lorig K, Stewart A, Ritter P, et al. Outcome Measures for Health Education and Other Health Care Interventions. Thousand Oaks, CA: Sage Publications; 1996.

[22] Peñarrieta DC, Vergel CO, Álvarez S, et al. Validacion de un instrumento para evaluar el automanejo en enfermedades crónicas en el primer nivel de atención en salud. Revista cientifica de Enfermería 2012; 8(1): 64-73.

[23] Peñarrieta-de Córdova I, Barrios FF, et al. Self-management in chronicconditions: partners in healthscaleinstrumentvalidation. Nursing Management. 2014; 20(10): 32-37.

[24] Ritter P, Stewart A, Kayma H, et al. Self-reports of health care utilization compared to provider records. Journal of Clinical Epidemiology. 2001; 54(2): 136-141. https://doi.org/10.1016/S0895-435 6(00) 00261-4

[25] Lorig K, Ritter P, Jacquez A. Outcomes of border health Spanish/English chronic disease self-management programs. The Diabetes Educator. 2005; 31(3): 401-9. PMid:15919640 https ://doi .org/ $10.1177 / 0145721705276574$

[26] Franek J. Self-management support interventions for persons with chronic disease: an evidence-based analysis. Ontario healthtechologyassessment series. 2013; 13(9): 1-60.

[27] Ritter PL, Ory MG, Laurent DD, et al. Effects of chronic disease selfmanagement programs for participants with higher depression scores: secondary analyses of an on-line and a small-group program. Translational behavioral medicine. 2014; 4(4): 398-406. PMid:25584089 https://doi.org/10.1007/s13142-014-0277-9

[28] Haslbeck J, Zanoni S, Hartung U, et al. Introducing the chronic disease self-management program in Switzerland and other Germanspeaking countries: findings of a cross-border adaptation using a multiple-methods approach. BMC Health Services Reserch. 2015; 15(576): 1-19.

[29] Lee MC, Wu SF, Hsieh NC, et al. "Self-Management Programs on eGFR, Depression, and Quality of Life among Patients with Chronic Kidney Disease: A Meta-Analysis." Asian Nursing Research. 2016; 10(4): 255-262. PMid:28057311 https://doi.org/10.1016/j . anr.2016.04.002

[30] Wang X, Hardin HK, Zhou L, et al. "Implementation and evaluation of the chronic-disease self-management program among Chinese immigrant older adults in the U.S." Geriatric Nursing. 2014; 35(6): 448450. PMid:25155476 https://doi.org/10.1016/j.gerinurs e.2014.07.002

[31] De Silva D. Evidence: helping people help themselves. A review of the evidence considering whether it is worthwhile to support selfmanagement. London: Health Foundation. 2011.

[32] Boger E, Ellis J, Latter S, et al. Self-Management and SelfManagement Support Outcomes: A Systematic Review and Mixed Research Synthesis of Stakeholder Views. Plos one. 2015; 10(7): 1-25. PMid:26162086 https://doi .org/10.1371/journal.po ne. 0130990

[33] Lorig K, Sobel D, Ritter P, et al. Effect of a self-management program on patients with chronic disease. Effective clinical practice: ECP. 2001; 4(6): 256-62. PMid:11769298

[34] Salvatore A, Ahn S, Jiang L, et al. National study of chronic disease self-management: 6-month and 12-month findings among cancer survivors and non-cancer survivors. Psycho-oncology. 2015; 24(12): 1714-1722. PMid:25871889 https://doi.org/10.100 2/pon. 3783

[35] Ahn S, Basu R, Smith ML, et al. The impact of chronic disease selfmanagement programs: healthcare savings through a community- 
based intervention. BMC Public Health. 2013; 13(1141): 2-6. https://doi.org/10.1186/1471-2458-13-1141

[36] Lawn S, Battersby M, Harvey P, et al. A behavioural therapy approach to self-management: the Flinders Program. Diabetes Voice. 2009; 54: 30-32.

[37] Williams A, Bloomfield L, Milthorpe E, et al. Effectiveness of mov- ing on: an Australian designed generic self-management program for people with a chronic illness. BMC Health Services Research. 2013; 13(90): 1-15. https://doi .org/10.1186/1472-6963-13-90

[38] Hoon E, Smith K, Black J, et al. Take Charge of Pain: evaluating a community-targeted self-management education program for people with musculoskeletal pain. Health Promotion Journal of Australia. 2016. PMid:27266857 https://doi .org/10.1071/HE15123 